\title{
CARACTERIZAÇÃO E AVALIAÇÃo PRODUTIVA DE UMA POPULAÇÃO NATIVA DE PIMENTA LONGA (Piper hispidinervum C.DC) NO SERINGAL CACHOEIRA, AC., BRASIL
}

\author{
Elias Melo de MIRANDA ${ }^{1}$
}

RESUMO - A busca de alternativas econômicas ao extrativismo tradicional na Amazônia é importante e a exploração de populações naturais de plantas da família Piperaceae, abundantes no Acre, pode se constituir em uma atividade rentável. $\mathrm{O}$ objetivo deste trabalho foi determinar algumas características demográficas, ecológicas e produtivas da espécie pimenta longa (Piper hispidinervum C.DC) e avaliar a possibilidade de seu manejo para a produção de óleo essencial com alto teor de safrol. O estudo foi desenvolvido no Projeto de Assentamento Extrativista Chico Mendes, em Xapuri, AC, em uma área de capoeira com aproximadamente dez anos, onde a pimenta longa era dominante. A população foi avaliada por meio de amostragem aleatória simples, com intensidade de $12 \%$, tendo como unidades amostrais parcelas de $10 \times 10 \mathrm{~m}$. Constatou-se uma densidade média de 15 indivíduos $/ 100 \mathrm{~m}^{2}$, variando de zero a 71 indivíduos. Esta população apresentou uma média de $92 \%$ de teor de safrol no óleo essencial, com CV de $2,38 \%$. O rendimento médio de óleo da biomassa seca, foi de $3,5 \%$, com $\mathrm{CV}$ de $28,57 \%$. A produção de óleo foi estimada em $12,11 \mathrm{~kg} / \mathrm{ha}$, com um corte por ano, que representa apenas $15,1 \%$ da produtividade obtida em áreas de cultivo. Portanto, a viabilidade da exploração dessas populações depende do desenvolvimento de técnicas que permitam aumentar a densidade de indivíduos. Ademais, na escolha de populações para o manejo, deve-se considerar características como: tamanho, densidade e idade da população.

Palavras-chave: Amazônia, biomassa, óleo essencial, safrol, manejo sustentado.

\section{Characterization and Yield Evaluation of a Native Population of Long Pepper (Piper hispidinervum C.DC) in an Extractive Reserve in the State of Acre, Brazil}

\begin{abstract}
The search for economic alternatives to traditional extractivism in Amazonia is important and the exploration of natural populations of plants of the Piperaceae family, which is abundant in Acre, can be a profitable activity. The objective of this study was to determine some demographic, ecological and yield characteristics of the species long pepper (Piper hispidinervum C.DC) and to evaluate the possibility of its management for the production of essential oil, with high safrole content. The study was done in the Chico Mendes Extractive Project, Xapuri, Acre, in a ten year old fallow, where long pepper was dominant. The population was evaluated through a $12 \%$ intensity random sample, with sampling plots of $10 \times 10 \mathrm{~m}$. A mean density of 15 individuals $/ 100 \mathrm{~m}^{2}$ was verified, varying from zero to 71 individuals. This population presented an average safrole content of $92 \%$ in the essential oil, with $\mathrm{CV}=2.38 \%$. The mean yield of oil in the dry biomass was $3.5 \%$, with $\mathrm{CV}=28.57 \%$. Oil yield was estimated at $12,11 \mathrm{~kg}$.ha- ${ }^{-1}$, with a single harvest/year, which represents $15,1 \%$ of the yield obtained in cultivation. The viability of the exploitation of these populations depends on the development of techniques to increase plant density. Furthermore, in the choice of populations for management, size, density and age of the population should be considered.
\end{abstract}

Key-words: Amazonia, biomass, essential oil, safrole, sustained yield management.

'Eng.-Agr. M.Sc. Embrapa Acre, Caixa Postal 321, 69907-980, Rio Branco-Acre. E-mail: elias@cpafac.embrapa.br 


\section{INTRODUÇÃO}

No estado do Acre o extrativismo vegetal ainda prevalece como atividade econômica importante, centrado na exploração da borracha natural e da castanha-do-brasil (Valverde, 1989). Estas duas espécies ainda aparecem como as principais fontes de renda das populações tradicionais.

Entretanto, nas condições atuais de mercado, a atividade extrativa já não proporciona uma renda mínima capaz de garantir a sobrevivência destas populações. Com base nos dados do Censo Agropecuário 19951996 (IBGE, 1998), estima-se que os ingressos obtidos da extração do látex e castanha, neste período, foi de apenas R\$ 976,56 por produtor. Os baixos preços praticados no mercado, a baixa produtividade das seringueiras e castanheiras e as restrições legais quanto ao uso da terra, limitam a viabilidade econômica desta atividade, especialmente no caso das reservas extrativistas (Smith et al., 1995).

As reservas extrativistas representam, do ponto de vista ecológico, um avanço na forma de uso da terra na Amazônia, podendo garantir a permanência dos ecossistemas florestais, pois baseiamse na exploração dos recursos naturais renováveis de forma potencialmente sustentada (Smith et al., 1995). Entretanto, além da necessária viabilidade ecológica, é preciso que se encontrem alternativas de produção compatíveis com a tradição e a cultura da população local, e que proporcionem um rendimento econômico que possibilite a sua sobrevivência em condições dignas (Homma, 1993). Somente assim será possível consolidar esta forma de uso da terra como uma alternativa viável também do ponto de vista econômico, garantindo a fixação destas populações no meio rural.

A pimenta longa (Piper hispidinervum C.DC) é um arbusto da família Piperaceae, com cerca de cinco metros de altura, encontrado em condições silvestres no vale do rio Acre, ocorrendo normalmente em áreas que sofreram ação antrópica, apresentando características de planta pioneira (Silva, 1993; Pimentel et al., 1998a; Silva \& Oliveira, 2000). A exploração do safrol, extraído de folhas e ramos secundários desta planta, pode constituir-se numa atividade rentável para os produtores rurais, pois a espécie vem despertando grande interesse de empresas nacionais e internacionais, processadoras de óleos essenciais.

O safrol é um fenil éter que ocorre como componente volátil em algumas plantas. Em sua forma mais pura, à temperatura ambiente, é um líquido viscoso de aroma canforáceo (Maia, 1987). É um componente aromático empregado pela indústria química como matéria-prima na manufatura de heliotropina, um importante fixador de fragrâncias, e butóxido de piperonila (PBO), usado como agente sinergístico nos inseticidas naturais (Castro \& Poveda, 1983).

A Itália é o principal fabricante de butóxido de piperonila, seguida do 
Japão. Os Estados Unidos da América são o maior mercado para outros produtos que usam safrol como matéria prima (Silva, 1993). A demanda por butóxido de piperonila tende a crescer cada vez mais, por ser biodegradável e possuir baixa toxicidade (Maia et al., 1993).

O safrol concentra-se nas folhas e ramos secundários, sendo extraído por processo de hidrodestilação, o que torna o sistema de produção para obtenção do produto bastante simples. Isto, aliado à rusticidade, precocidade e facilidade de manejo da cultura, faz crer que o beneficiamento utilizando microdestiladores caseiros, poderá ser viável para pequenos produtores rurais, especialmente se forem reunidos em associações ou cooperativas.

A pimenta longa ainda é uma espécie praticamente desconhecida do ponto de vista científico, existindo poucos trabalhos sobre o cultivo dessa planta. Apesar do pouco conhecimento gerado sobre a cultura, Rocha Neto et al. (1999) apresentaram os coeficientes técnicos para o seu cultivo, mostrando a viabilidade econômica do empreendimento.

Dados sobre o cultivo de pimenta longa são raros e contraditórios. A produtividade depende da técnica de manejo adotada, especialmente do número de cortes anuais (geralmente um ou dois), do espaçamento e da altura e da época de corte. Silva (1993), trabalhando com plantas provenientes de estacas, obteve rendimentos de óleo essencial de 65 e $130 \mathrm{~kg} / \mathrm{ha}$, usando espaçamentos de $0,60 \times 1,20 \mathrm{~m}$ e $0,60 \times 0,60 \mathrm{~m}$, respectivamente. No campo experimental da Embrapa Acre foram obtidos rendimentos máximos de 250 $\mathrm{kg} / \mathrm{ha}$, com espaçamento de $0,70 \mathrm{x}$ $0,70 \mathrm{~m}$, fazendo a correção do solo e adubação com NPK. Dados mais recentes, obtidos em áreas de produtores na localidade de Extrema, RO, mostraram rendimentos médios em torno de $160 \mathrm{~kg} / \mathrm{ha}$, com dois cortes anuais (dados não publicados),

As populações nativas de pimenta longa, até o momento, receberam pouca atenção da pesquisa, em termos de estudos para a utilização do seu potencial produtivo. Todavia, acredita-se que populações com elevado teor de safrol, que ocorrem abundantemente em áreas de capoeira e pastagens degradadas, necessitam ser melhor estudadas e manejadas com fins produtivos, pois podem ser uma opção para aumentar a oferta de safrol no mercado mundial.

O conhecimento da autoecologia da espécie é de fundamental importância para esta proposição e para o desenvolvimento de técnicas de manejo que permitam o aproveitamento deste valioso recurso. O objetivo deste trabalho foi determinar algumas características demográficas, ecológicas e produtivas de uma população de pimenta longa, em área de ocorrência natural e avaliar a possibilidade do seu manejo para a produção de óleo essencial com alto teor de safrol.

\section{MATERIAL E MÉTODOS}

Os estudos foram desenvolvidos no Projeto de Assentamento Extrativista Chico Mendes (Seringal 
Cachoeira), localizado a $30 \mathrm{~km}$ da sede do Município de Xapuri, com acesso pela rodovia BR 317. A cobertura vegetal é do tipo floresta densa, apresentando solos bem drenados classificados como Podzólico Vermelho Amarelo, com argila de atividade baixa, textura variando de argilosa a média, com as seguintes características químicas: $\mathrm{pH}=4,9\left(\mathrm{em} \mathrm{H}_{2} \mathrm{O}\right) ; \mathrm{P}=1,0 \mathrm{mg} \mathrm{dm}^{-3}$; $\mathrm{K}^{+}=0,50 \mathrm{mmol}_{\mathrm{c}} \mathrm{dm}^{-3} ; \mathrm{Ca}^{+}=13,1 \mathrm{mmol}_{\mathrm{c}}$ $\mathrm{dm}^{-3} ; \quad \mathrm{Mg}^{++}=10,6 \quad \mathrm{mmol}_{\mathrm{c}} \quad \mathrm{dm}^{-3}$; $\mathrm{Al}^{+++}=4,9 \mathrm{mmol}_{\mathrm{c}} \mathrm{dm}^{-3} ; \mathrm{H}^{+}+\mathrm{Al}^{+++}=2,2$ $\mathrm{mmol}_{c} \mathrm{dm}^{-3}$. O clima da região é do tipo Ami (Köppen), apresentando elevado índice pluviométrico anual (mais de $1900 \mathrm{~mm}$ ), com pequeno período seco. A temperatura média anual é $24,5^{\circ} \mathrm{C}$. O relevo da área varia de ondulado a suave ondulado.

Foi selecionada uma área de capoeira de 2,0 ha, originária de um roçado tradicional, que encontrava-se em pousio por aproximadamente dez anos, onde a população de pimenta longa era dominante. A população foi inventariada por meio de uma amostragem aleatória simples (Cochran, 1977), com 24 parcelas de $10 \times 10 \mathrm{~m}$, correspondendo a uma intensidade amostral de $12 \%$. Dentro de cada parcela foi contado o número de indivíduos da espécie e medidos altura, diâmetro basal, diâmetro de copa e peso da biomassa fresca de folhas e ramos secundários das plantas. A relação entre estas variáveis foi estabelecida por meio de análise de correlação e regressão, ajustando modelos de regressão linear simples e múltipla, usando o peso da matéria fresca como variável dependente e as demais variáveis medidas no campo como independentes, a fim de estimar a produção de biomassa fresca da população. A análise dos resíduos da regressão com os dados originais mostrou heterogeneidade da variância, sendo então os dados ajustados usando a transformação logarítmica-Ln x (Snedecor \& Cochran, 1980).

Foi determinado o teor de umidade da matéria fresca, usando amostras secas em estufa, a $80^{\circ} \mathrm{C}$, até atingirem peso constante, a qual foi usada para estimar a produção de matéria seca de folhas e ramos secundários na área de estudo. Foram coletadas amostras de folhas e ramos secundários de plantas de pimenta longa, para a determinação do teor de safrol e o rendimento de óleo em base úmida e seca.

Após a primeira avaliação da população foram realizadas amostragens a cada oito meses, por mais dois anos, a fim de determinar a reação da espécie ao manejo e sua resposta em termos de produção de biomassa. Os rendimentos obtidos foram avaliados usando o teste não paramétrico de Wilcoxon para a comparação das médias (Hollander \& Wolfe, 1973).

\section{RESULTADOS E DISCUSSÃO}

$\mathrm{O}$ inventário constatou a presença de 365 indivíduos na área amostrada, o que corresponde a uma densidade de um indivíduo a cada $6,58 \mathrm{~m}^{2}$ e uma média de 15,2 indivíduos $/ 100 \mathrm{~m}^{2}$, com limite de 
confiança de $\pm 7,8$ indivíduos, o que corresponde a um erro amostral de $51 \%$. Desta forma, a distribuição demográfica da espécie na área estudada mostrou alta variabilidade, evidenciada por um coeficiente de variação de $125 \%$, sendo esta uma característica intrínseca à população.

Dentre as 24 unidades amostrais, três apresentaram-se vazias, ou seja, sem a presença de indivíduos da espécie em estudo, e a parcela de maior densidade apresentou um total de 71 indivíduos. A freqüência de parcelas por classe de número de indivíduos aproxima-se da distribuição binomial negativa (Fig. 1), que caracteriza-se por apresentar a variância maior que a média, devido ao padrão de distribuição da população da espécie na área ser do tipo agregado (Matteucci \& Colma, 1982; Ludwig \& Reinolds, 1988).
Segundo Greig-Smith (1983) o comportamento e desempenho das plantas são afetados por vários fatores internos (intrínsecos da planta) e externos (características ambientais). Muitos destes fatores são conhecidos apenas superficialmente, faltando estudos que expliquem as interações entre variáveis. No caso da pimenta longa, espécie em processo de domesticação, ainda não existem estudos que expliquem de forma consistente o comportamento da espécie no campo (Silva, 1993).

A população apresentou as seguintes médias para as variáveis de crescimento avaliadas: altura $5,07 \mathrm{~m}$, diâmetro basal $6,31 \mathrm{~cm}$ e diâmetro de copa $2,10 \mathrm{~m}$. A estrutura demográfica da população, quanto ao diâmetro basal, apresentou a distribuição mostrada na figura 2 , onde verifica-se a presença de um maior número de

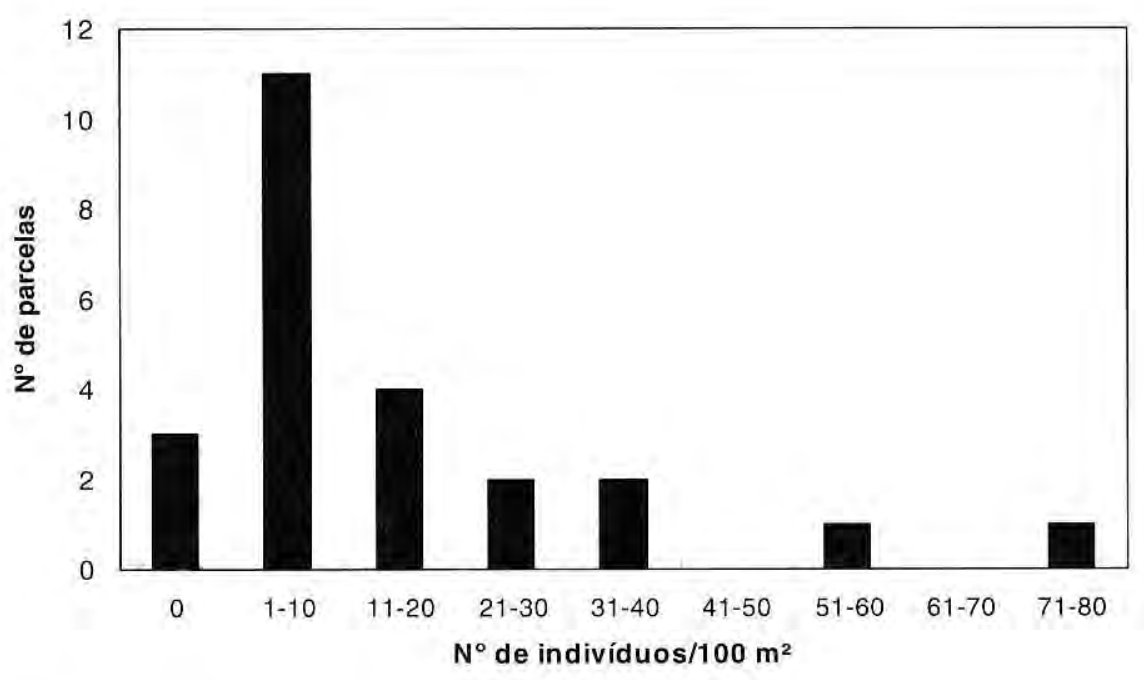

Figura 1. Histograna de frequiência de parcelas por classe de número de indivíduos de uma população nativa de pimenta longa, no Seringal Cachoeira, em Xapuri-AC. 
indivíduos nas classes de menor diâmetro, sugerindo que a população, aparentemente coetânea, apresenta regeneração abundante, o que pode constituir-se numa vantagem para o manejo da espécie.

Durante o período do estudo, a regeneração de pimenta longa, tanto proveniente de sementes como de rebrotações, competiu livremente com as demais espécies, sem qualquer tratamento adicional, além do corte das plantas de maior porte para extração de óleo. A pimenta longa apresentou alta capacidade de competição, superando as demais espécies com seu rápido crescimento. Isto pode significar economia de mão-de-obra nos sistemas de manejo da espécie.

A análise de correlação determinou o grau de dependência entre as variáveis de crescimento e o peso da biomassa fresca. Foram encontradas correlações positivas $(\mathrm{p}<0,01)$ entre as variáveis para todas as comparações realizadas, com coeficientes superiores a 0,70 , mostrando que a produção de biomassa está diretamente correlacionada com o porte da planta, com destaque para o diâmetro de copa com um coeficiente de 0,83 .

Os resultados da análise de regressão linear simples para a variável peso da matéria fresca, tendo como variáveis independentes a altura, diâmetro basal e diâmetro de copa das plantas, são apresentados nas figuras 3, 4 e 5 . Também foi ajustado um modelo de regressão múltipla para

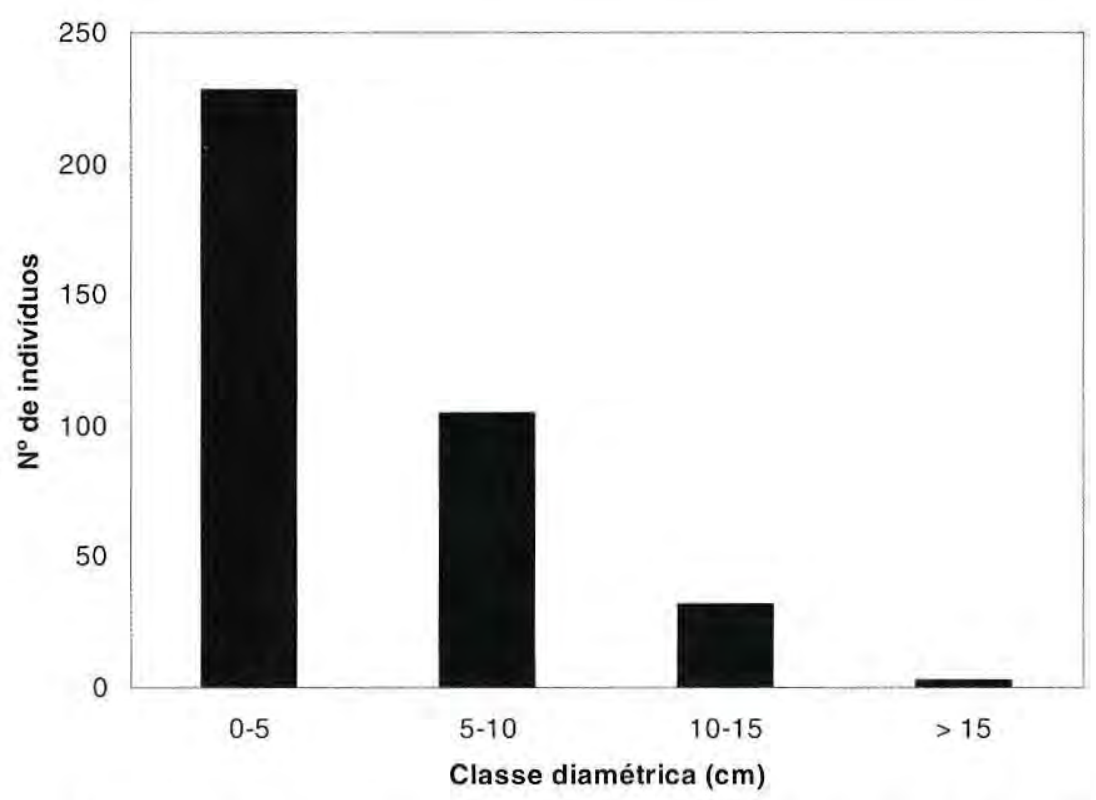

Figura 2. Distribuição diamétrica de uma população nativa de pimenta longa, no Seringal Cachoeira, em Xapuri-AC. 


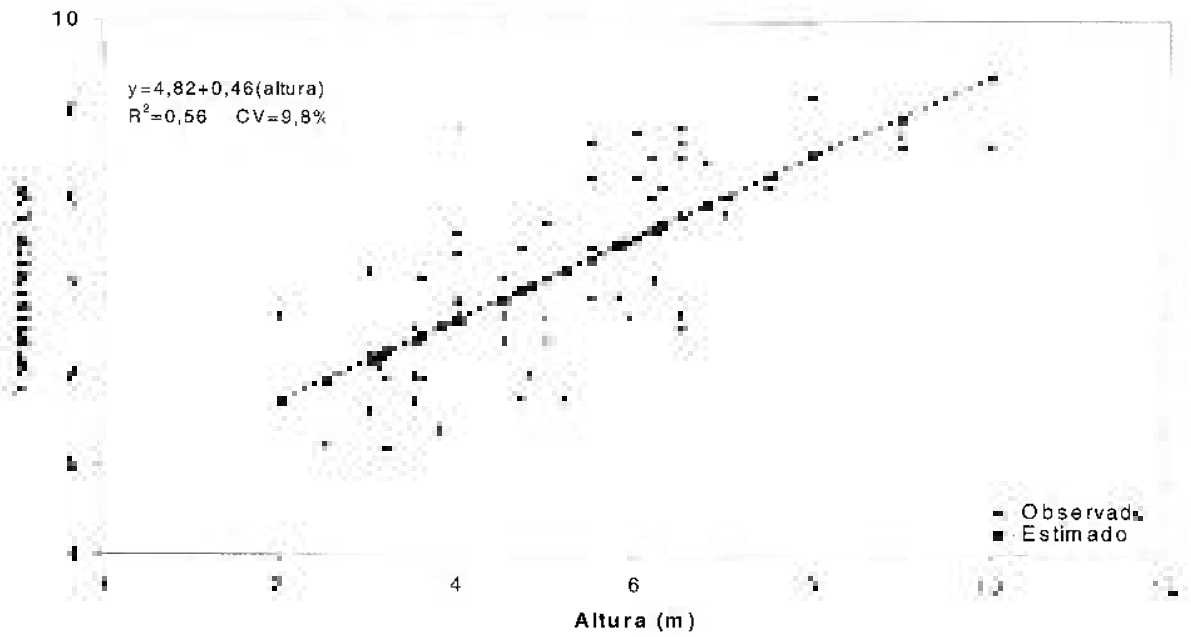

Figura 3. Regressão linear simples ajustada para estimar a produção de biomassa fresca em função da altura de plantas de uma população nativa de pimenta longa, no Seringal Cachoeira, em Xapuri-AC.

10

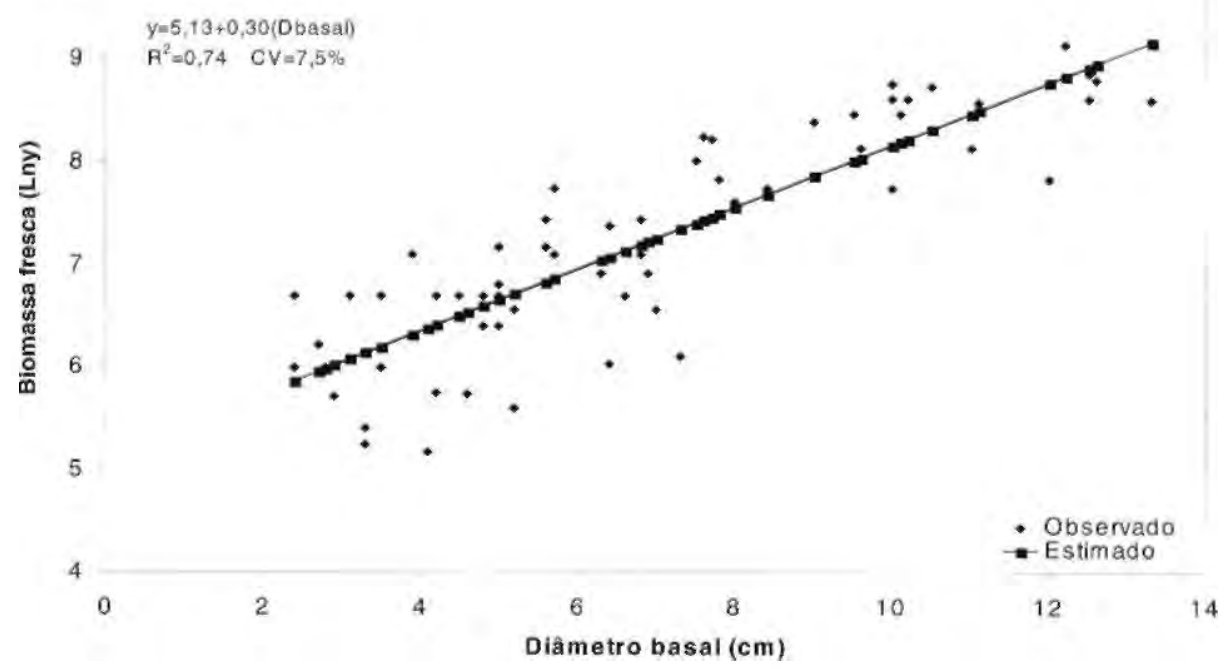

Figura 4. Regressão linear simples ajustada para estimar a produção de biomassa fresca em função do diâmetro basal de plantas de uma população nativa de pimenta longa, no Seringal Cachoeira, em Xapuri-AC. 


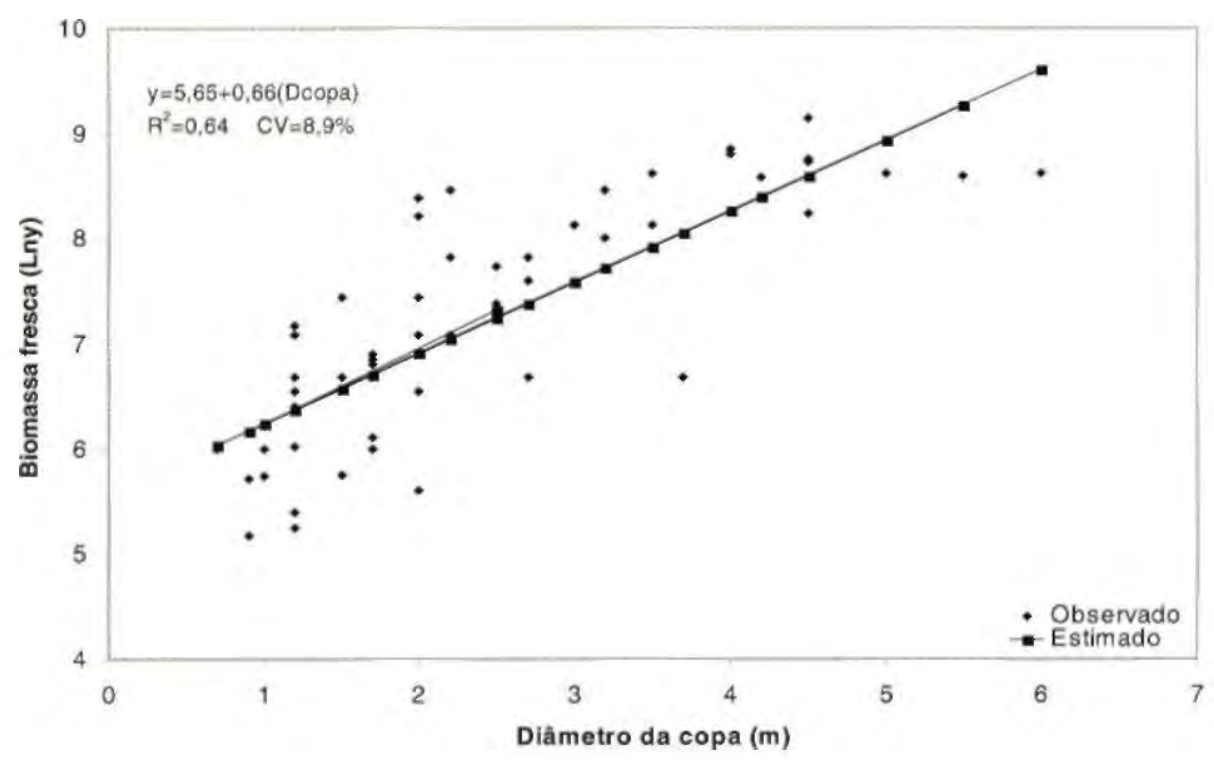

Figura 5. Regressāo linear simples ajustada para estimar a produção de biomassa fresca em funçāo do diâmetro de copa de plantas de uma população nativa de pimenta longa, no Seringal Cachoeira, em Xapuri-AC.

explicar a relação entre o peso da matéria fresca e as variáveis de crescimento medidas no campo, a equação ajustada foi a seguinte:

$\mathrm{pm} \mathrm{m}=4,97+0,08(\mathrm{~h})+$ $0,19(\mathrm{db})+0,22(\mathrm{dc})$

Onde: $p m f=$ peso da matéria fresca de folhas e ramos secundários (g); h=altura total da planta $(\mathrm{m})$; $\mathrm{db}=$ diâmetro basal $(\mathrm{cm})$; $\mathrm{e}$ $\mathrm{dc}=$ diâmetro da copa $(\mathrm{m})$.

O grau de ajuste foi satisfatório $\left(\mathrm{R}^{2}=0,77 ; \mathrm{CV}=7,14 \%\right)$, sendo o modelo significativo $(p<0,01)$. Dentre os parâmetros estimados para as variáveis independentes usadas no modelo, a altura total mostrou-se não significativo $(p>0,05)$. Isto mostra que a altura está explicando pouco da variação na biomassa de folhas e ramos finos das plantas. Este fato decorre do processo natural de competição entre as plantas de populações nativas onde, geralmente, os indivíduos apresentem-se estiolados, de forma que sua altura não influencia diretamente no volume da copa.

O peso da matéria fresca das plantas amostradas foi transformado em peso seco usando-se o índice 0,25189 , proveniente da relação peso seco/peso fresco obtida em laboratório, indicando que o teor médio de umidade das amostras no campo foi de $75 \%$. A produção de biomassa na área amostrada foi estimada em $109,50 \mathrm{~kg}$, o que dá uma média de $4,56 \mathrm{~kg} / 100 \mathrm{~m}^{2}$ e $0,46 \mathrm{~kg}$ de matéria seca por planta, considerando 
apenas indivíduos com mais de $1 \mathrm{~m}$ de altura (238 plantas).

A média de teor de safrol na população foi superior a $92 \%$, tendo como valores extremos 84,88 e $98,22 \%$. As plantas mostraram pouca variabilidade para esse caráter, com coeficiente de variação de apenas $2,38 \%$. Esta população também apresentou um bom rendimento de óleo em base seca, com uma média de $3,5 \%$, e um coeficiente de variação $28,57 \%$. Estes índices mostram um alto rendimento dos caracteres associados à produção, o que pode facilitar o manejo da população para fins extrativos.

As plantas apresentaram rebrotação vigorosa, repondo em um curto período grande parte da biomassa perdida após cada corte. Estimativas da produção de biomassa e de óleo essencial nos três cortes realizados, são apresentadas na tabela 1 .

Observaram-se rendimentos decrescentes, após os sucessivos cortes. Isso pode ser explicado pelo fato da biomassa obtida no primeiro corte ter sido acumulada ao longo dos anos de existência das plantas. No segundo e terceiro ano os cortes ocorreram em períodos de apenas oito meses, tempo insuficiente para as plantas reporem toda a biomassa perdida, considerando-se o estresse fisiológico provocado pelo desfolhamento total da planta. Ocorreu uma redução na produtividade de biomassa de $29,20 \%$ do primeiro para o segundo corte, de $41,33 \%$ do primeiro para o terceiro, e de $17,15 \%$ do segundo para o terceiro corte (Tab. 1).

Apesar de se observar uma queda anual no rendimento, existe diferença significativa $(\mathrm{p}<0,05)$ apenas entre a média obtida em 1996 (16,00 $\mathrm{kg} / \mathrm{ha}$ ) quando comparada com a de $1998(9,22 \mathrm{~kg} / \mathrm{ha})$, pelo teste não paramétrico de Wilcoxon. Como por ocasião do primeiro corte havia um maior acúmulo de biomassa e não foi encontrada diferença significativa $(p>0,05)$ entre o segundo e terceiro cortes, não há evidências de que os rendimentos se manterão decrescentes, pelo menos a curto prazo.

$\mathrm{O}$ rendimento médio de óleo essencial da população no período do estudo, estimado em $12,11 \mathrm{~kg} / \mathrm{ha} / \mathrm{ano}$ (Tab. 1), representa somente cerca de $15,1 \%$ do rendimento obtido em área de cultivo, considerando a média de 80 $\mathrm{kg} / \mathrm{ha} /$ corte, obtida em Extrema, RO.

Tabela 1. Estimativa de produção de biomassa e óleo essencial em uma área de população nativa de pimenta longa ao longo de três cortes consecutivos, no seringal Cachoeira, em Xapuri, AC.

\begin{tabular}{lcccc}
\hline Variável & \multicolumn{4}{c}{ Rendimento $(\mathrm{kg} / \mathrm{ha})$} \\
\cline { 2 - 5 } & 1996 & 1997 & 1998 & Média \\
\hline Biomassa fresca & 1811,00 & 1272,31 & 1054,14 & 1379,15 \\
Biomassa seca & 452,75 & 318,08 & 263,53 & 344,79 \\
Óleo essencial & $16,00^{*}$ & $11,13^{*}$ & $9,22^{*}$ & $12,11^{*}$ \\
\hline
\end{tabular}

*Considerando o rendimento médio de $3,5 \%$ da biomassa seca. Densidade do safrol @ 1,0 kg/l. 
Isto representa um rendimento cerca de 6,6 vezes menor, o que é coerente com a diferença de densidade das plantas nos dois sistemas, ou seja, 1.500 plantas/ha estimada para a população em estudo e 10.000 plantas/ ha usarido o espaçamento de $1 \times 1 \mathrm{~m}$, recomendado para o cultivo da pimenta longa (Pimentel et al., 1998b). Estes dados mostram que o rendimento médio de biomassa por planta não difere significativamente nos dois sistemas de exploração.

Como a viabilidade econômica da exploração não foi objeto do presente estudo, os resultados obtidos não permitem conclusões definitivas sobre este aspecto. Entretanto, devido à baixa produtividade verificada, quando comparada com o cultivo, a viabilidade desta atividade dependerá das condições de mercado, bem como da geração de tecnologia que permita o adensamento destas populações, visando aumentar a produtividade de biomassa. Outros fatores que devem ser considerados para a exploração extrativa dessa espécie são o tamanho, densidade e idade da população, variáveis diretamente correlacionadas com a produção de biomassa.

\section{CONCLUSÕES}

A população de pimenta longa estudada apresentou como característica demográfica um padrão de distribuição espacial tipo agregado, freqüência variando de zero a 71 indivíduos $/ 100 \mathrm{~m}^{2}$, com média de 15,2 indivíduos $/ 100 \mathrm{~m}^{2}$. O teor médio de umidade da matéria fresca foi de $75 \%$ e o rendimento de óleo da matéria seca de $3,5 \%$, com teor de safrol superior a $92 \%$. A espécie apresentou regeneração abundante e alta capacidade de rebrota após o corte. A produtividade média de óleo essencial em três cortes realizados, com intervalo de oito meses, foi de $12,11 \mathrm{~kg} / \mathrm{ha}$.

$\mathrm{O}$ aproveitamento de populações nativas de pimenta longa para a produção de óleo essencial parece factível, apesar do baixo rendimento obtido. A espécie apresenta características ecológicas favoráveis ao manejo, além da possibilidade de adensamento da população por meio da regeneração natural ou do enriquecimento com plantio de mudas na área. Isto pode elevar o rendimento da cultura e viabilizar a exploração.

\section{Bibliografia citada}

IBGE. 1998. Censo Agropecuário: 1995-1996. Instituto Brasileiro de Geografia e Estatística. Rio de Janeiro. Vol.. 3, p.126151 .

Castro, C.; Poveda, L. 1983. Piper auritum H.B.K: estudio preliminar de aceite essencial de sus hojas. Ins. Cienc. Quim. Prod. Nat., 7(1/2):24-25.

Cochran, W.G. 1977. Sampling Techniques. $3^{\text {th }}$ ed. Wiley, New York. 428p.

Greig-Smith, P. 1983. Quantitative Plant Ecology, $3^{\text {th }}$ ed. Blackwell, Oxford. 359p.

Hollander, M.; Wolfe, D.A. 1973. Nonparametric Statistical Methods. Wiley, New York. 503p.

Homma, A.K.O, 1993. Extrativismo vegetal na Amazônia: limites e oportunidades. EMBRAPA-SPI, Brasília. 202p.

Ludwig, J.A.; Reynolds, J.F. 1988. Statistical Ecology. A Primer on Methods and Computing. Wiley, New York. 337p.

Maia, J.G. 1987. Espécies de Piper da Amazônia ricas em safrol. Química Nova, 
10(3):200-204.

Maia, J.G.; Green, C.L.; Milchard, M.J. 1993. New sources of natural safrole. Perfumer \& Flavorist, 18:19-22.

Matteucci, S.D.; Colma, A. 1982. Metodologia para el Estudio de la Vegetación. OEA, Washington, D.C. 169p.

Pimentel, F.A.; Pereira, J.B.M.; Oliveira, M.N. 1998a. Zoneamento e caracterização de habitats de pimenta longa (Piper hispidinervum) no Acre. Boletim de Pesquisa, 20. Embrapa-CPAF/AC, Rio Branco, Acre. 17p.

Pimentel, F.A.; Sousa, M.M.M.; Sá, C.P.; Cabral, W.G.; Silva, M.R.; Pinheiro, P.S.N.; Bastos, R.M. 1998 b. Recomendações básicas para o cultivo de pimenta longa (Piper hispidinervum) no Estado do Acre. Circular Técnica, 28. Embrapa-CPAF/AC, Rio Branco, Acre. $14 \mathrm{p}$.

Rocha Neto, O.G.; Oliveira Júnior, R.C.; Carvalho, J.E.U.; Lameira, O.A. 1999. Principais produtos extrativos da Amazônia e seus coeficientes técnicos. IBAMA-Centro Nacional de Desenvolvimento Sustentado das Populações Tradicionais, Brasília. p.4147.

Silva, M.H.L. 1993. Tecnologia de cultivo e produção racional da Pimenta longa (Piper hispidinervium). Dissertação de Mestrado, UFRRJ, Itaguaí, Rio de Janeiro. $87 \mathrm{p}$.

Silva, A.C.P.R.; Oliveira, M.N. 2000. Produção e dispersão de sementes de pimenta longa (Piper hispidinervum). Boletim de Pesquisa, 24. Embrapa-CPAF/ AC, Rio Branco, Acre. $14 \mathrm{p}$.
Smith, N.J.H.; Serrão, E.A.S.; Alvim, P.T.; Falesi, I.C. 1995. Amazonia: Resiliency and Dynamism of the Land and its People. United Nations University Press, Tokio, Japão. 253p.

Snedecor, G.W.; Cochran, W.G. Statistical Methods. $7^{\text {th}}$. ed. Iowa State University Press, Ames, Iowa, U.S.A. 507p.

Valverde, O. (Coord.). 1989. A Organização do Espaço na Faixa da Transamazônica: Acre e regiōes vizinhas. IBGE, Rio de Janeiro. V.2. 224p. 